\title{
What's in a face? The impact of nonlinguistic 'ethnic' facial features on accent perception
}

\author{
Dr Susana A. Eisenchlas* and Dr Rowan B. Michael \\ School of Humanities, Languages and Social Science, Griffith University, Nathan, \\ Australia \\ *s.eisenchlas@griffith.edu.au
}

\begin{abstract}
Sociolinguistic research on language attitudes has revealed that non-standard accented speakers are usually perceived more negatively than members of the dominant speech community. Few studies, however, have examined whether a speaker's ethnicity, evidenced by nonlinguistic factors such as appearance, may play a role in listeners' perception of accent. This project is based on studies by Rubin (1992) investigating perceptions of foreign academics by undergraduate students in the US. In those studies, participants listened to a short lecture presented with a projection of either a Caucasian or a Chinese face and completed a listening comprehension test and a speakers' evaluation rating scale. Unknown to the participants, the recording was produced by a single standard American-English speaker. Participants exposed to the Chinese face perceived a non-standard accent and rated the speaker more negatively than those exposed to the Caucasian face. Our present study extends Rubin (1992) by examining data collected through an online survey from languages and linguistics university students in Australia. Unlike Rubin's (1992) findings, this study found no statistically significant differences between responses based on exposure to a Chinese or Caucasian face, a fact that could be attributed primarily to the multilingual and multicultural composition of Australian universities.
\end{abstract}

Keywords: Language attitudes; reverse linguistic stereotyping; non-standard accents; matched guise technique

\section{Introduction}

Research on individual and group categorisation and perception provides ample evidence that impressions about others are often guided less by the content of speakers' 
messages and more by non-content features of speakers (Giles, Wilson, and Conway, 1981). One of the strongest non-content verbal factors affecting perception is accents (Gill and Badzinski, 1992). Accents refer to regional phonological variations of speech, as opposed to dialects, which involve grammatical and lexical differences as well (Crystal, 1987). An accent is a feature that can identify a speaker's affiliation to a national, ethnic, or socioeconomic group and may cause the hearer to connect the speaker with generalised or stereotypical perceptions associated with the group (Eisenchlas and Tsurutani, 2011). This process can trigger disparaging or other negative perceptions, both among those who self-identify as members of the dominant speech community (Lambert, Hodgson, Gardner and Fillenbaum, 1960) and among members of minority ethnic groups (Seggie, Smith, and Hodgins, 1986).

Most studies on language attitudes concur that participants often report more positive perceptions of sources with the same accent as themselves, and less positive perceptions of other-accented sources (Gill, 1994; Gill and Badzinski, 1992). Furthermore, most scholars have found that speakers' evaluations become more negative with increasing accentedness (Eisenstein, 1983, but see Eisenchlas and Tsurutani, 2011 for different findings).

An extensive body of research on speaker's evaluation has shown that nonstandard accents have been used to infer personality traits. In one of the earliest studies conducted in the USA, comparing listeners' attitudes towards Americans and Europeans (Italians, Eastern Europeans and Norwegians), American speakers were rated significantly higher in Socio-Intellectual Status, even though the Europeans had progressed further in their post-baccalaureate study than the Americans. Americans were also rated higher than Europeans in Aesthetic Quality, although all speakers had been screened for unusual vocal quality, and in Dynamism (Mulac, Hanley, and Prigge, 
1974). Standard accented speakers have typically been judged more positively on traits relating to ambition, competence and ability. Conversely, non-standard accented speakers have been judged more positively on traits relating to friendliness, honesty and helpfulness (Ball, 1983; Callan and Gallois, 1982, 1983, 1987). Similarly, in Great Britain, speakers with Received Pronunciation British accent were seen as having higher status, competence, intelligence, self-confidence and industriousness than regional and urban British accents, who were rated higher on personal integrity and features of social attractiveness, such as sincerity, kind-heartedness and generosity (Giles, Wilson, and Conway, 1981). In another study, standard Anglo-Australian English speakers were seen as more intelligent, competent, and less sociable than broad Anglo-Australian or Italian-American speakers (Seggie et al., 1986). Higher personality ratings of speakers with prestige accents were obtained also from members of ethnic minority groups. Seggie et al. (1986) research on language attitudes in Australia showed that Aboriginal and Greek-Australians provided a higher rating for Anglo-Australian speakers than to speakers of their own background within a status-oriented setting, such as an educational institution.

Attributions of success and failure have also been linked to accent information (Gill and Badzinski, 1992), as accents can foster the impression that the non-standard accented speaker belongs to a lower socio-economic class than the mainstream speaker (Gill, 1994). In a study conducted in the USA, American speakers were rated as having a higher socio-intellectual status than European speakers even though the European speakers had progressed further academically (Mulac et al., 1974). In another study conducted in Great Britain, judges indicated that they preferred standard and middleclass speakers to non-standard and working class speakers (Giles and Sassoon, 1983). Even when participants were told that a non-standard speaker belong to the middle 
class, they still awarded the non-standard accented speaker a low status evaluation (Giles and Sassoon, 1983). A meta-analysis of 20 studies examining the effect of nonstandard accents and speaker evaluations, conducted by Fuentes, Gottdiener, Martin, Gilbert and Giles (2011) in the USA, provides evidence of the robustness of this phenomenon.

These trends have been shown to have real life detrimental implications in highstakes decisions (Lippi-Green, 2012). Non-standard accented speakers frequently face discrimination based on the perceived level of 'accentedness' of their speech. This has been investigated in areas such as employment (Callan and Gallois, 1987; Giles, Wilson and Conway, 1981; Gill and Badzinski, 1992; Lindemann, 2003; Seggie et al., 1982), access to housing (Purnell, Idsardi and Baugh, 1999), credibility in the judicial system (Frumkin, 2007), and educational opportunities (Anderson-Clark, Green and Henley, 2008; Elhoweris, Mutua, Alsheikh and Holloway, 2005), to mention just a few areas of disadvantage.

Discrimination based on non-native accents has also been reported in higher education. Negative evaluations of international students based on accent can result in them being offered fewer opportunities for class participation, being given lower marks in speech-related activities or side-lined in classroom activities (Munro, Derwing and Sato, 2006; Nakane, 2006).

The focus of this paper is on the evaluation of academics in higher education, and thus we now turn to the discussion of the few studies that explored language attitudes to non-standard accented academics.

\section{Non-standard accented academics}

One of the most visible aspects of the internationalisation of higher education is the increasing presence of foreign born and trained academics employed in English 
speaking countries. Despite this growing trend, there is very little research on university students' attitudes towards non-standard accented academics. If the findings from contexts briefly mentioned above extend to higher education, there is reason to expect that non-standard accented academics would face challenges in gaining acceptability. This is because, as discussed above, speakers with non-standard accents are disadvantaged in situations that are perceived as requiring competence or ability (Eisenstein, 1983; Boyd, 2003; Seggie et al., 1986; Lippi Green, 2012), and are viewed as less educated and having lower status (Giles and Sassoon, 1983) than their mainstream speaking colleagues.

One of the most frequent sources of complaint against non-standard accented academics relates to lack of intelligibility stemming from the 'foreign' accent. One study found that over $40 \%$ of participants dropped out of courses with non-native teachers (Rubin and Smith, 1990). In another study, North American students rated North American English accented teachers more favourably than British or Malaysian accented teachers, rating the Malaysian accented teacher least favourably (Gill, 1994). Students also reported greater recall with the North American teacher. It has been posited that as students delegate more mental resources to understanding the accent, less effort may be directed towards processing the message (Gill, 1994). These results indicate that the cognitive load required in understanding the accent may have hindered recall efforts in some participants (Gill, 1994). To remedy this situation, non-standard accented teachers are often required to attend training workshops to remediate their communication skills, placing the onus on the teachers to improve the classroom environment (Rubin and Smith, 1990). This 'solution' does not bode well for nonstandard accented teachers. Research indicates that phonological patterns may be the 
aspect of language most resistant to change after puberty (Piske, MacKay and Flege, 2001).

However, intelligibility problems -real or perceived- do not tell the whole story. Research indicates that listeners' language attitudes may also affect their comprehension abilities. Thus Rubin and Smith (1990) showed that student ratings of their non-native teachers' language and teaching ability were unrelated to objective experts' ratings, but were related to pre-existing social stereotypes (Rubin and Smith, 1990). This phenomenon, which Kang and Rubin (2009) called "reverse linguistic stereotyping" is characterised by listeners "hearing" "the pronunciation that they expect to hear, sometimes with little regard to the actual properties of the acoustic signal.' (Rubin, 2012: 11). In a comprehensive overview of studies on accent perceptions across diverse disciplines (i.e., perceptual psychology, sociolinguistics, and phonetics), Lindemann and Subtirelu (2013: 567) similarly conclude that 'listeners demonstrate a certain amount of reliability in their ratings of speakers stemming from shared expectations of a speaker's language and social groups, rather than from the speech itself.' To mention a final example, Yi, Phelps, Smiljanic and Chandrasekaran (2013) examined whether visual cues affected native listeners' perceptions of speech produced by native and non-native (in this case, Korean) speakers of English, under two conditions: audio-only and audio-visual guises. They found that, while visual cues about the speaker enhanced word intelligibility for native English speech, they reduced intelligibility for non-native speech. The authors attributed these results to listeners' implicit non-linguistic visual biases interacting with phonetic perception in such a way that affected speech processing.

These findings are problematic in tertiary education, because researchers found that participants' perceptions of the instructors' accent were the strongest predictors of 
how they rated the teachers, regardless of whether their perceptions were accurate or not. When participants believed an instructor to have a 'foreign' accent they rated him or her poorly (Rubin and Smith, 1990; Gill, 1994).

Evidence has shown, however, that familiarity with accents improves one's comprehension skills (Rubin, 1992). Rubin and Smith (1990) found that participants who had been in classes with non-native teachers before were less likely to drop out of their subsequent classes with non-native teachers or report that being in that class had hurt their grades. They also reported improved listening comprehension, indicating that with increased exposure students' attitudes may adjust. Kang (2008) also found that trained participants' short exposure to the international teaching assistants changed their views about the teaching assistants' accents, finding them less accented. Similarly, Eisenchlas and Tsurutani (2011), in one of the few such studies conducted in Australia, found that Australian participants showed favourable attitudes towards speakers with non-standard accents. However, this may have been due to the fact that the participants were all studying foreign languages and linguistics.

Given that most of the studies reviewed concluded that non-standard accented speakers are judged negatively, and -more crucially- that the perception of a 'foreign' accent could be motivated by extra-linguistic factors, such as the speaker's physical appearance, the present study used an adaption of Rubin (1992) to explore the following research questions:

(1) Can the exposure to a 'foreign face' trigger reverse linguistic stereotyping?

(2) Does the perception of a 'foreign accent' result in negative speaker's evaluations? 
(3) If so, does the 'foreign accented speech negatively impact on listening comprehension?

\section{The Study}

\section{Context}

The presence of expatriate academics is highly noticeable in Australia, a country of great multicultural and linguistic diversity. $29 \%$ of the population, i.e., 7.1 million migrants was born in nearly 200 countries and over 300 languages are spoken (Australian Bureau of Statistics, 2018). According to the 2016 census, nearly $21 \%$ of the population aged over 5 years speak a language other than English at home, i.e. more than one in five Australians is a minority language speaker. Despite the country's demographic composition, language attitude studies conducted in Australia provide ample evidence that Anglo-Australians remain strongly monolingual and Anglophile in their attitudes towards 'foreign' accents when evaluating personality traits related to speakers' competence (Ball, 1983; Callan and Gallois, 1982, 1983, 1987; Seggie et al. 1982). Eisenchlas and Tsurutani's (2011) findings, however, point to a possible change in attitudes towards non-standard accented academics, although their pool of participants was quite limited and consisted of languages and linguistics students, which may have biased their results (See also Kang and Rubin 2009 for the positive impact of studies in languages and linguistics on listening comprehension skills).

\section{Methodology}

This study was designed as an adaptation of Rubin's (1992) study, exploring whether non-linguistic factors such as ethnicity could affect American undergraduates' perceptions of non-native English-speaking teaching assistants. As discussed in the 
literature review, perceptions of speakers based on their speech may stem from stereotypes about a putative group, i.e., on social cues, and have little relation with the speech these speakers actually produce. Rubin (1992) speculated that, if expectations of a non-standard accent based on nonlinguistic features can impact on accent perception and speaker evaluation, even in the unlikely event that a speaker could modify their accent and sound nativelike, their speech may still not be perceived as such by prejudiced listeners.

Rubin's (1992) first study motivated the present research and thus is the focus here. The study used a matched guised technique typical of language and attitude studies (See Lambert et al., 1960). The rationale of the matched guise technique is 'to eliminate effects on speech perception due to idiosyncratic differences in voice quality and style among speakers' (Rubin 2012: 20).

Participants in Rubin's (1992) study included 62 North-American native English-speaking undergraduate students of basic speech communication classes. The data collection involved Students listening to a four-minute tape-recorded lecture on an unfamiliar topic featuring a female university 'instructor', whose face, either Caucasian or Chinese, was projected on a screen. Participants were randomly assigned to either the Caucasian or the Chinese condition. Unbeknown to them, however, the lecture was recorded by a single speaker, a native speaker of English. Immediately following the lecture, students were tested on their listening comprehension by means of a cloze test in which every seventh word was omitted and asked to evaluate the speaker on a number of personality traits. Results show that 'when they were faced with an ethnically Asian instructor, participants responded in the direction one would expect had they been listening to non-standard speech' (1992: 519), i.e., students reported that the presumed 'Chinese' lecturer had non-standard accented speech. More important, the mere visual 
exposure to the instructor's ethnicity lead to negative ratings of the speaker, and undermined the participants' listening comprehension. Rubin concluded that, 'at least among this particular sample of undergraduates even vigorous pronunciation training for NNSTA [non-native speaking teaching assistants] will matter little' (1992: 519). While the present study was inspired by Rubin's (1992), and similarly used a matched guise technique, there were important differences between the two studies, including participants' background, mode of delivery, time and place of testing, and type of materials. These differences will be explained in what follows.

\section{Participants}

\section{Experiment 1}

Participants were recruited from a first semester first year undergraduate class at a large comprehensive Australian university. This class is taken by linguistics and communication students, and thus is the closest to Rubin's (1992) 'basic speech communication' class. Most participants $97.2 \%(n=106)$ identified as students while $2.8 \%(n=2)$ identified as 'other'. Most participants $70.6 \%(n=77)$ were female and $29.4 \%(n=32)$ were male. The demographic information of these participants is shown in Appendix 1 (See Table 1). Unlike Rubin (1992), which focused only on data collected from local students, the data collected for this project included both international and domestic students with participants holding 21 different nationalities, as shown in Appendix 1 (See Table 2). This adaptation was made to reflect the increasingly multicultural composition of Australian universities, and in response to findings reported by Seggie et al. (1986) suggesting that the non-native speakers of English may also have negative, and sometimes even less tolerant (Fayer and Krasinski, 1987, reactions to non-standard accented speakers. The majority of participants $69.7 \%$ 
$(\mathrm{n}=76)$ identified their country of origin as Australia; $10.1 \%(\mathrm{n}=11)$ as Greater China; $3.7 \%(n=4)$ as New Zealand; $1.8 \%(n=2)$ as Philippines; $1.8 \%(n=2)$ as Malaysia; and 0.9\% $(\mathrm{n}=1)$ as Colombia, South Africa, Japan, USA, Indonesia, Scotland, Papua New Guinea, Sweden, Germany, Norway, Russia, Singapore, and India respectively. The majority $82.6 \%(n=90)$ of participants also listed their native language as English; $10.1 \%(\mathrm{n}=11)$ identified Chinese as their native language; one participant listed themselves as bilingual English/Chinese; and all other participants listed a single other language as their native language. All participants $(n=109)$ indicated they had studied at least one foreign language and $50.5 \%(\mathrm{n}=55)$ indicted that, apart from their mother tongue, they spoke at least one other language fluently.

After completing the questionnaire, the deceptive nature of the photographs was revealed to participants in a written debrief. Participants were given an opportunity to withdraw from the project and have all responses deleted. Only participants who gave consent had their responses recorded $(n=109)$. Around 30 per cent of participants withdrew at this point. Since results may have been impacted by the large number of withdrawals, permission was obtained from the Ethics Committee to withhold information with regards to the nature of the photos. Experiment 2 was then carried out to verify the findings obtained in Experiment 1.

\section{Experiment 2}

A different cohort of participants was recruited from undergraduate linguistics classes at the same large comprehensive Australian university. Most participants 95.1\% $(n=136)$ identified as students while $4.9 \%(\mathrm{n}=7)$ identified as 'other'. The majority of participants $71.3 \%(n=102)$ were female and $27.3 \%(n=39)$ were male. The demographic information of these participants is shown in Appendix 1 (See Table 1). 
As per experiment 1, the data collected for this project contained both International and domestic students with participants holding 52 different nationalities, as shown in Appendix 1 (Table 2) This diversity was naturally occurring in the data sample and reflects the increasingly multicultural composition of Australian universities. The largest group of participants $47.6 \%(n=68)$ identified their country of origin as Australia; 11.2\% ( $\mathrm{n}=16)$ as 'Greater China' (including PRC China, Hong Kong, Macau, and Taiwan); $4.2 \%(n=6)$ as New Zealand; 3.5\% $(n=5)$ as Japan; $2.1 \%(n=3)$ as the United States; $1.4 \%(n=2)$ as Philippines; and $0.7 \%(n=1)$ as one of 41 other countries. The majority $54.9 \%(n=78)$ of participants also listed their native language as English; $10.1 \%(n=11)$ identified Chinese as their native language; one participant listed themselves as bilingual English/Chinese; and all other participants listed a single other language as their native language. Many participants $76.2 \%(n=109)$ indicated they had studied at least one foreign language and $73.4 \%(\mathrm{n}=105)$ indicated that, apart from their mother tongue, they spoke at least one other language. Detailed demographic information about participants is given in Appendix 1.

\section{Procedure (Experiments 1 and 2)}

Unlike Rubin's (1992) study, which was based on data collected during class time, participants completed the task individually online at a time and place of their choosing. Administering an online survey ensures voluntary participation without coercion and also provides a disinhibiting effect on participants, whereby there is often an increased level of honesty (Dewaele and McCloskey, 2015). Each participant listened to a digitally recorded speech sample produced a male speaker of Standard American English, lasting 4 minutes and 20 seconds. As each participant listened they were randomly shown either an Asian face or a Caucasian face. The speaker's ethnicity was operationalised by the display of the photo presumably representing the instructor, 
although this was not made explicit. Standard American English selected instead of Australian English as this was neutrally different for all participants

The photos were selected from a royalty free stock photos website which contained photos of actual university professors. To limit confounding factors, such as age, status, or physical attractiveness, the photos selected were from two male subjects of a similar age (between 35-40 years old), similarly dressed and photographed from the shoulders up. The photos had the same screen resolution and size.

Participants accessed the experiment via a weblink and after completing basic demographic questions were exposed to the digital recording whilst simultaneously exposed to either the Caucasian or Asian face. Immediately after listening to the digital recording, participants were asked to complete six multiple choice comprehension questions based on the talk and to rate the speaker using a 7-point semantic differential scale ranging from 1 (not at all) to 10 (very). The scale (adapted from Bell, 1983 and Eisenchlas and Tsurutani 2011) included 12 personality traits (i.e., entertaining, intelligent, understandable, confident, sincere, competent, kind, knowledgeable, patient, friendly, organised, and cool) in random order, that fall under the categories of 'competence', 'integrity' and 'social attractiveness' typically used in this type of studies.

The comprehension questions appeared on one webpage and the speaker rating questions on the following webpage. After completing both sections participants were given an opportunity to respond to the following open-ended question "Would you like to make any comment about the speaker (positive or negative)?”.

\section{Materials}

The speech, simulating a section of a university lecture and supposedly presented by a "lecturer" was recorded from a TED ED talk delivered by psychologist Philip Zimbardo 
and titled "Why are boys struggling?" (http://ed.ted.com/lessons/philip-zimbardo-thedemise-of-guys). The lecture topic chosen was one that was academic but not drawn from the discipline of the participants, yet was expected to be of interest to participants. This was designed to prevent a lowering of response rates due to boredom either through the topic or an over lengthy script. The multiple choice comprehension questions based on the lecture and given to participants were the ones developed by the TED ED team.

Results

\section{Experiment 1}

An independent groups $t$ - test demonstrated that participants exposed to an Asian face while listening to the talk $(M=4.92, S D=.73)$ did not rate the personality traits of the speaker more negatively than those viewing the Caucasian face while listening $(M=$ $4.79, S D=1.280), t(104.559)=.632, p=.529$. In fact, their ratings were slightly higher but the differences were not statistically significant (See Appendix 2, Table 3).

Chi-square tests did not detect any statistically significant differences between those viewing the Asian face and Caucasian face on any of the 6 comprehension test items ( $p>.05$ for all tests) (See Appendix 3, Table 5).

Participants in the Asian face and Caucasian face groups reported similar ratings for each of the presenter adjectives (See Table 1). However, participants viewing the Asian face reported a marginally statistically significant lower rating of the presenter's sincerity $(M=7.06, S D=1.58)$ than participants who viewed Caucasian face $(M=7.67$, $S D=1.47), p=.048$. No other significant differences were observed $(p>.05$ for all tests). 
The data was split by face, an independent groups t-test demonstrated that participants with English as their first language $(M=5.069, S D=.651)$ who viewed the Asian face had a statistically significant higher overall comprehension score than participants with a first language other than English exposed to the same face $(M=$ $4.286, S D=.756), t(34)=2.773, p=.009$. However, there was no statistically significant difference in the overall average rating of the speaker.

For participants that viewed the Caucasian face, an independent groups t-test demonstrated that participants with English as their first language $(M=5.016, S D=$ 1.109) who viewed the Caucasian face had a significantly higher overall comprehension score than participants with a first language other than English exposed to the same face $(M=3.546, S D=1.508), t(71)=3.832, p<.001$. However, there was no significant difference in the overall average rating of the speaker.

\section{Experiment 2}

An independent groups $t$ - test demonstrated that participants exposed to an Asian face while listening to the talk $(M=4.53, S D=1.491)$ did rate the speaker slightly more negatively than those viewing the Caucasian face while listening $(M=4.59, S D$ $=1.276), t(140)=-2.58, p=.798$. While their ratings were slightly more negative the differences were not statistically significant (See Appendix 2, Table 4).

No statistically significant differences were observed on any of the 12 presenter adjectives between participants who viewed the Asian face and participants who viewed the Caucasian face $(p>.05$ for all tests).

Chi-square tests did not detect any statistically significant differences between those viewing the Asian face and Caucasian face on any of the 6 comprehension test items ( $p>.05$ for all tests) (See Appendix 3, Table 6). 
The data was split by face, an independent groups t-test demonstrated that participants with English as their first language $(M=4.97, S D=1.224)$ who viewed the Asian face had a significantly higher overall comprehension score than participants with a first language other than English exposed to the same face $(M=4.03, S D=1.623)$, $t(71)=2.828, p=.006$. However, there was no significant difference in the overall average rating of the speaker.

For participants that viewed the Caucasian face, an independent groups t-test demonstrated that participants with English as their first language who were exposed to the same face $(M=5.10, S D=.940)$ who viewed the Caucasian face had a significantly higher overall comprehension score than participants with a first language other than English $(M=3.93, S D=1.363), t(49.097)=4.02, p<.001$. However, there was no significant difference in the overall average rating of the speaker.

\section{Discussion}

Based on Rubin's (1992) study and subsequent research on reverse linguistic stereotyping, it was expected that the data would show a bias against the 'foreign' face; moreover, based on Seggie et al. (1986), we expected a similar negative bias from international students. This expectation was not borne out among this study's university-student participants, as no significant differences based on exposure to a Caucasian or Asian face were found. Analysis of the data showed that participants in both experiment 1 and experiment 2 did not allow the photo to which they were exposed to affect their comprehension, nor did participants negatively evaluate the speaker on the basis of their face. This was in direct contrast to Rubin's (1992) findings, where the mere exposure to an Asian face led participants to perceive a foreign accent, which in turn resulted in negative speaker's evaluation and poorer listening comprehension. 
While participants in Rubin's (1992) and the present study were largely similar in terms of age (17-22), occupation (students), courses of studies (i.e., Speech Communication vs Communication: A Linguistic Approach), level of study (undergraduate), there are two major differences between Rubin's (1992) study and ours, the first related to the demographic composition of participants, the second to the. context of the studies, which varied in time and place.

With regards to demographic factors, one major difference between the studies was the ethnolinguistic composition of participants: Rubin excluded international students from the data while our study did not. Our decision not to exclude international students was based on the high level of diversity that characterises Australian universities.

According to the Institute of International Education (2017), the percentage of international students enrolled in the higher education sector in American institutions for the period $2015 / 2016$ was $5.2 \%$ (up from $4 \%$ at the time when Rubin conducted his studies), while the international student population in Australia during the same period was considerably higher at $20.7 \%$. This difference becomes more marked when we consider regional variations within each country. Our study was conducted in a large comprehensive Australian university where $27 \%$ of students are international, while Rubin's studies were restricted to Ohio, Georgia and Arizona, where the intake of international students is lower than the US average.

Moreover, while Rubin does not specify the percentage of overseas born and trained academics working at the university where his study was conducted, our study was conducted in a highly multicultural setting, where a large number of staff are international. Thus, a possible explanation for the positive evaluation of a speaker with a non-Caucasian face may be that participants are constantly exposed to speakers of 
diverse ethnicities, including a high proportion of overseas born academics and students. This environment could have fostered a favourable attitude towards ethnolinguistic diversity.

Another possible factor that could have impacted on the results relates to the linguistic background of our participants. While there is no information on the linguistic repertoire of Rubin's students, there was a high level of bi/multilingualism in our participants: $17.4 \%$ of Experiment 1 participants and $45.1 \%$ of Experiment 2 listed a language other than English as their native language; most participants indicated that they had studied at least another language, and almost all were currently studying a foreign language. Moreover, as linguistics students, they were (or at least expected to be more) aware of the sociolinguistic variables that impact on communication. Whether participants developed positive evaluations of 'foreign-looking' speakers as a result of studying languages and linguistics, or whether a positive predisposition towards diverse speakers influenced their decision to study these disciplines is a conceptually and practically interesting question, although it is beyond the scope of our study.

Another important point of difference relates to the timeframe where the studies were conducted: 23 years separate the two studies. During that period, Australian universities have become highly multicultural, reflecting an increasingly diverse ethnic composition of society.

A final factor that could have impacted on the results was the online administration of the experiments, vis-à-vis Rubin's, which were conducted in a classroom situation. Given that, as mentioned above, online survey completion can have a disinhibiting effect on participants, resulting in an increased level of honesty (Dewaele and McCloskey, 2015), we doubt that the medium was a relevant factor. Determining this, however, is a matter that would require further empirical research. 


\section{Conclusion}

This study explored whether the perception of a 'foreign' accent could be motivated by extra-linguistic factors, such as the speaker's physical appearance (question 1) and, if so, whether this perception would result in negative speaker's evaluation (question 2) which would in turn affect listening comprehension (question 3).

In contrast with previous studies, the results indicate that languages and linguistic students did not evidence reverse linguistic stereotyping through the mere exposure to a 'foreign' face (question 1), did not show differences in their evaluation of Caucasian vs Asian speakers (question 2) and exposure to different faces did not have any negative impact on listening comprehension (question 3). We attribute these unexpected results to the multilingual and multicultural context of Australian higher education. However, further research is needed to corroborate these findings.

Although some researchers typically refrain from publishing non-statistically significant findings, we argue that this practice may lead to a publication bias, where valuable insights may be lost. The fact that two separate research experiments were conducted reinforces our argument that the multicultural and multilingual setting of the study may mitigate negative perceptions due to non-linguistic factors, such as an 'ethnic' face. Further research into more homogenous communities is therefore needed to corroborate this argument.

\section{References}

Anderson-Clark, Tracy, Raymond Green and Tracy Henley. 2008. "The relationship between first names and teacher expectations for achievement motivation." Journal of Language and Social Psychology 27(1): 94-99. doi:10.1177/0261927X07309514. 
Australian Bureau of Statistics (2017) 2024.0 - Census of Population and Housing: Australia Revealed, 2016. Accessed 29 Oct 2018.

Australian Bureau of Statistics (2018) Migration, Australia, 2016-17. http://www.abs.gov.au/AUSSTATS/abs@.nsf/Latestproducts/3412.0Main\% 20Features32016-

17?opendocument\&tabname=Summary \&prodno=3412.0\&issue=2016$17 \&$ num $=\& v i e w=$. Accessed 29 Oct 2018.

Ball, Peter. 1983. Stereotypes of Anglo-Saxon and non-Anglo-Saxon accents: Some exploratory Australian studies with the matched guise technique. Language Sciences, 5(2): 163-183. doi: 10.1016/S0388-0001(83)80021-7.

Boyd, Sally. 2003. "Foreign-born teachers in the multilingual classroom in Sweden: The role of attitudes to foreign accent." International Journal of Bilingual Education and Bilingualism 6(3/4): 283-295. doi:10.1080/13670050308667786.

Callan, Victor., and Cynthia Gallois. 1982. "Language attitudes of Italo-Australian and Greek-Australian bilinguals." International Journal of Psychology 17(1/4): 345-358. doi: 10.1080/00207598208247450.

Callan, Victor., and Cynthia Gallois. 1983. “Anglo-Australian attitudes towards immigrants: A review of survey evidence." International Migration Review 17(1): 120-137.

Callan, Victor., and Cynthia Gallois. 1987. “Anglo-Australians' and immigrants' attitudes toward language and accent: A review of experimental and survey research." International Migration Review, 21(1): 48-69.

Crystal, David. 1987. The Cambridge Encyclopaedia of Language. Cambridge: Cambridge University Press. 
Dewaele, Jean-Marc, and James McCloskey. 2015. “Attitudes towards foreign accents among adult multilingual language users." Journal of Multilingual and Multicultural Development 36(3): 221-238.

Eisenchlas, Susana, and Chiharu Tsurutani. 2011. "You sound attractive! Perceptions of accented English in a multi-lingual environment." Australian Review of Applied Linguistics 34(2): 216-236.

Eisenstein, Miriam. 1983. "Native reactions to non-native speech: A review of empirical research." Studies in Second Language Acquisition 5(2): 160-176. doi: $10.1017 / S 0272263100004836$.

Elhoweris, Hala., Kagendo Mutua, Negmeldin Alsheikh, and Pauline Holloway. 2005. "Effect of children's ethnicity on teachers' referral and recommendation decisions in gifted and talented programs." Remedial and Special Education 26(1): 25-31. doi: 10.1177/07419325050260010401.

Fayer, Joan, and Emily Krasinski, 1987. Native and Nonnative Judgments of Intelligibility and Irritation. Language Learning 37(3): 313-326. doi:10.1111/j.1467-1770.1987.tb00573.x.

Frumkin, Lara. 2007. Influences of accent and ethnic background on perceptions of eyewitness testimony. Psychology, Crime \& Law, 13(3), 317-331. doi: $10.1080 / 10683160600822246$.

Fuertes, Jairo, William Gottdiener, Helena Martin, Tracy Gilbert, and Howard Giles. 2011. A Meta-Analysis of the Effects of Speakers' Accents on Interpersonal Evaluations. European Journal of Social Psychology 42: 120-133. doi:10.1002/ejsp.862.

Giles, Howard, Pamela Wilson, and Anthony Conway. 1981. “Accent and lexical diversity as determinants of impression formation and perceived 
employment suitability." Language Sciences 3(1): 91-103. doi: 10.1016/S03880001(81)80015-0.

Giles, Howard, and Caroline Sassoon. 1983. The effect of speaker's accent, social class background and message style on British listeners' social judgements. Language \& Communication 3(3): 305-313. doi:10.1016/0271$5309(83) 90006-X$

Gill, Mary. 1994. “Accent and stereotypes: Their effect on perceptions of teachers and lecture comprehension." Journal of Applied Communication Research 22(4): 348-361. doi: 10.1080/00909889409365409.

Gill, Mary. And Diane Badzinski. 1992. "The impact of accent and status on information recall and perception formation." Communication Reports 5(2): 99-106. doi: 10.1080/08934219209367552.

Institute of International Education. 2015/16. “Higher Education Sector Most Recent". Accessed January 25, 2017. http://www.iie.org/Services/ProjectAtlas/United-States/Higher-Education-Sector

Kang, Okim. 2008. "Ratings of L2 oral performance in English: Relative impact of rater characteristics and acoustic measures of accentedness." in Spaan Fellow Working Papers in Second or Foreign Language Assessment: Volume 6 edited by J. S. Johnson, 181-201. Michigan: English Language Institute, University of Michigan.

Kang, Okim. And Donald Rubin. 2009. "Reverse linguistic stereotyping: Measuring the effect of listener expectations on speech evaluation." Journal of Language and Social Psychology 28(4): 441-456. doi: 10.1177/0261927X09341950. 
Lambert, W., R. Hodgson, R. Gardner and S. Fillenbaum. 1960. “Evaluational Reactions to Spoken Language." Journal of Abnormal and Social Psychology 60(1): 44-51. doi: 10.1037/h0044430.

Lindemann, Stephanie. 2003. Koreans, Chinese or Indians? Attitudes and ideologies about non-native English speakers in the United States. Journal of Sociolinguistics, 7(3): 348-364. doi:10.1111/1467-9481.00228.

Lindemann, Stephanie, ad Nicholas Subtirelu. 2013. Reliably biased: The role of listener expectation in the perception of second language speech. Language Learning, 63(3): 567-594. doi: 10.1111/lang.12014.

Lippi-Green, Rosina. 2012. English with an Accent: Language, ideology, and discrimination in the United States. (2nd ed.) New York: Routledge.

Mulac, Anthony, Theodore Hanley and Diane Prigge. 1974. "Effects of phonological speech foreignness upon three dimensions of attitude of selected American listeners." Quarterly Journal of Speech 60(4): 411-420. doi: 10.1080/00335637409383250.

Munro, Murray, Tracey Derwing, and Kyoko Sato. 2006. "Salient accents, covert attitudes: Conciousness raising pre-service second language teachers." Prospect 21(1): 67-79. URL:http://www.ameprc.mq.edu.au/docs/prospect_journal/volume_21_no_ 1/21_1_4_Munro.pdf

Nakane, Ikuko. 2006. "Silence and politeness in intercultural communication in university seminars." Journal of Pragmatics 38(11): 1811-1835. Doi:10.1016/j.pragma.2006.01.005. 
Piske, Thorsten, Ian MacKay and James Flege. 2001. "Factors affecting degree of foreign accent in an L2: A review." Journal of phonetics 29(2): 191-215. doi:10.006/jpho.2001.0134.

Purnell, Thomas, William Idsardi and John Baugh. 1999. Perceptual and phonetic experiments on American English dialect identification. Journal of Language and Social Psychology, 18(1): 10-30. doi: 10.1177/0261927X99018001002.

Rubin, Donald. 1992. “Nonlanguage factors affecting undergraduates' judgments of nonnative English-speaking teaching assistants." Research in Higher Education 33(4): 511-531. URL: http://www.jstor.org/stable/40196047

Rubin, Donald. 2012. "The power of prejudice in accent perception: Reverse linguistic stereotyping and its impact on listener judgments and decisions." In Proceedings of the 3rd Pronunciation in Second Language Learning and Teaching Conference, Sept. 2011, edited by J. Levis and K. LeVelle, 11-18. Ames, IA: Iowa State University. doi: 10.13140/RG.2.1.1465.4485.

Rubin, Donald, Stuart Ainsworth, Eunsook Cho, Don Turk, and Laura Winn. 1999. “Are Greek letter social organizations a factor in undergraduates' perceptions of international instructors?" International Journal of Intercultural Relations 23(1): 1-12. doi: 10.1016/S0147-1767(98)00023-6.

Rubin, Donald, and Kim Smith. 1990. "Effects of accent, ethnicity, and lecture topic on undergraduates' perceptions of nonnative English-speaking teaching assistants." International Journal of Intercultural Relations 14(3): 337-353. doi: 10.1016/0147-1767(90)90019-S.

Seggie, Ian, Carmel Fulmizi, and Judy Stewart. 1982. "Evaluations of personality traits and employment suitability based on various Australian accents." Australian Journal of Psychology, 34(3): 345-357. 
Seggie, Ian, Nancy Smith, and Patricia Hodgins. 1986. "Evaluations of employment suitability based on accent alone: An Australian case study." Language Sciences 8(2): 129-140. doi: 10.1016/S0388-0001(86)80011-0.

Yi, Han-Gyol, Jasmine Phelps, Raika Smiljanic, and Bharath Chandrasekaran. 2013. Reduced efficiency of audiovisual integration for nonnative speech. The Journal of the Acoustical Society of America, 134(5), EL387-EL393.

[INSERT APPENDIX 1, TABLES 1 \& 2]

[INSERT APPENDIX 2, TABLES 3 \& 4]

[INSERT APPENDIX 3, TABLES 5 \& 6]

\section{Appendix 1: Demographic information}

Table 1: Participants Demographics

\begin{tabular}{|c|c|c|c|}
\hline Demographic & Characteristic & $\begin{array}{c}\text { Experiment } 1 \\
(n=109)\end{array}$ & $\begin{array}{c}\text { Experiment } 2 \\
(n=143)\end{array}$ \\
\hline \multirow[t]{3}{*}{ Sex } & Male & $29.4 \%$ & $27.3 \%(n=39)$ \\
\hline & Female & $70.6 \%$ & $71.3 \%(n=102)$ \\
\hline & Other & - & $0.7 \%(n=1)$ \\
\hline \multirow[t]{3}{*}{ Language spoken } & English & $82.6 \%(n-90)$ & $54.5 \%(\mathrm{n}=78)$ \\
\hline & Chinese & $10.1 \%(n=11)$ & $14.7 \%(n=21)$ \\
\hline & Other & $7.3 \%(n=)$ & $30.8 \%(n=44)$ \\
\hline Studied a foreign language & & $100 \%$ & $100 \%$ \\
\hline Speak another language & & $50.5 \%(\mathrm{n}=55)$ & - \\
\hline
\end{tabular}


Table 2: Participants Country of Origin

\begin{tabular}{lll}
\hline Country of origin & \multicolumn{1}{c}{$\begin{array}{c}\text { Experiment } 1 \\
(n=109)\end{array}$} & \multicolumn{1}{c}{ Experiment 2} \\
& \multicolumn{1}{c}{$(n=143)$} & $47.6 \%(n=68)$ \\
Australia & $69.7 \%(n=76)$ & $11.2 \%(n=16)$ \\
China (TW, HK, MU) & $10.1 \%(n=11)$ & $4.2 \%(n=6)$ \\
New Zealand & $3.7 \%(n=4)$ & $1.4 \%(n=2)$ \\
Philippines & $1.8 \%(n=2)$ & 0 \\
Malaysia & $1.8 \%(n=2)$ & $3.5 \%(n=5)$ \\
Japan & $0.9 \%(n=1)$ & $2.1 \%(n=3)$ \\
United States & $0.9 \%(n=1)$ & $1.4 \%(n=2)$ \\
Spain & $0.9 \%(n=1)$ & 41 other \\
Other countries each & 11 other countries & $28.7 \%(n=41)$ \\
& $0.9 \%(n=1)$ per country &
\end{tabular}

\section{Appendix 2: Speaker Evaluation Results}

Table 3: Speaker Evaluation Experiment 1

\begin{tabular}{lccccc}
\hline & \multicolumn{2}{c}{ Asian face $(\mathrm{n}=36)$} & \multicolumn{4}{c}{ Caucasian face $(\mathrm{n}=73)$} & \\
& $\mathrm{M}$ & $\mathrm{SD}$ & $\mathrm{M}$ & $\mathrm{SD}$ & $\mathrm{p}=$ \\
& & & & & \\
\hline Entertaining & 7.83 & $(1.52)$ & 7.84 & $(1.52)$ & .94 \\
Intelligent & 7.72 & $(1.71)$ & 8.1 & $(1.25)$ & .19
\end{tabular}




\begin{tabular}{lccccc} 
Understandable & 7.92 & $(1.23$ & 7.85 & $(1.60)$ & .83 \\
Confident & 8.36 & $(1.29)$ & 8.3 & $(1.60)$ & .85 \\
Sincere & 7.06 & $(1.59)$ & 7.67 & $(1.47)$ & .048 \\
Competent & 7.69 & $(1.37)$ & 8.11 & $(1.32)$ & .13 \\
Kind & 7.08 & $(1.86)$ & 7.53 & $(1.71)$ & .21 \\
Knowledgeable & 7.86 & $(1.52)$ & 8.33 & $(1.27)$ & .09 \\
Patient & 6.64 & $(2.00)$ & 7.22 & $(1.69)$ & .12 \\
Friendly & 7.92 & $(1.71)$ & 8.23 & $(1.37)$ & .34 \\
Organised & 7.78 & $(1.61)$ & 8.07 & $(1.62)$ & .38 \\
Cool & 7.53 & $(2.08)$ & 7.49 & $(1.89)$ & .93 \\
Average & 7.62 & $(1.16)$ & 7.89 & $(1.67)$ & .24 \\
\hline
\end{tabular}

Table 4: Speaker Evaluation Experiment 2

Asian face $(n=74) \quad$ Caucasian face $(n=68) \quad P=$

\begin{tabular}{lccccc} 
& $\mathrm{M}$ & $\mathrm{SD}$ & $\mathrm{M}$ & $\mathrm{SD}$ & \\
& & & & & \\
\hline Entertaining & 7.03 & 2.35 & 7.24 & 2.34 & .76 \\
Intelligent & 7.80 & 1.66 & 7.54 & 1.81 & .18 \\
Understandable & 7.26 & 2.15 & 6.99 & 1.91 & .43 \\
Confident & 8.18 & 1.74 & 8.07 & 1.83 & .17 \\
Sincere & 7.60 & 1.87 & 7.16 & 2.04 & .55 \\
Competent & 7.85 & 2.05 & 7.38 & 1.96 & .82 \\
Kind & 7.27 & 2.24 & 7.18 & 1.95 & .44 \\
Knowledgeable & 8.16 & 1.77 & 8.01 & 1.68 & .59
\end{tabular}




\begin{tabular}{llllll} 
Patient & 6.80 & 2.05 & 6.66 & 2.03 & .52 \\
Friendly & 7.66 & 2.11 & 7.79 & 1.71 & .15 \\
Organised & 7.42 & 2.00 & 7.57 & 1.92 & .61 \\
Cool & 6.42 & 2.70 & 6.67 & 2.38 & .17 \\
Average & 7.45 & 1.68 & 7.35 & 1.61 & .71 \\
\hline
\end{tabular}

\section{Appendix 3: Listening Comprehension Results}

Table 5: Comprehension Results for Experiment 1

\begin{tabular}{llll}
\hline \multirow{2}{*}{$\begin{array}{l}\text { Comprehension } \\
\text { Questions }\end{array}$} & \multicolumn{3}{c}{ Ethnicity } \\
\cline { 2 - 3 } & $\begin{array}{c}\text { Asian Face } \\
\text { Count (\%group) }\end{array}$ & $\begin{array}{l}\text { Caucasian Face } \\
\text { Count (\%group) }\end{array}$ & \\
\hline Q1 Correct & $30(27.5 \%)$ & $55(50.5 \%)$ & .34 \\
Q2 Correct & $33(30.3 \%)$ & $66(60.6 \%$ & .83 \\
Q3 Correct & $26(23.9 \%)$ & $53(48.6 \%)$ & .97 \\
Q4 Correct & $24(11 \%)$ & $56(51.4 \%)$ & .26 \\
Q5 Correct & $31(4.6 \%)$ & $54(49.5 \%)$ & .15 \\
Q6 Correct & $33(30.3 \%)$ & $66(60.6 \%)$ & .83
\end{tabular}

Table 6: Comprehension Results for Experiment 2

\begin{tabular}{llll}
\hline Comprehension & \multicolumn{2}{c}{ Ethnicity } & \\
\cline { 2 - 3 } & $\begin{array}{c}\text { Asian Face } \\
\text { Count (\%group) }\end{array}$ & $\begin{array}{l}\text { Caucasian face } \\
\text { Count (\%group) }\end{array}$ & \\
\hline Q1 Correct & $53(71.62 \%)$ & $41(60.3 \%)$ & 1.61 \\
Q2 Correct & $60(82.19 \%)$ & $57(85.07 \%)$ & 0.82 \\
Q3 Correct & $49(67.12 \%)$ & $44(65.67 \%)$ & 0.86 \\
Q4 Correct & $53(72.60 \%)$ & $56(82.35 \%)$ & 0.23 \\
Q5 Correct & $59(79.73 \%)$ & $56(82.35 \%)$ & 0.83 \\
Q6 Correct & $62(84.93 \%)$ & $58(85.29 \%)$ & 1.00 \\
\hline
\end{tabular}

